\title{
METODOLOGIA DE GMC INTENSIVO PARA REDUZIR QUEDA DE CARVÃO VEGETAL NAS CORREIAS TRANSPORTADORAS*
}

Rosiane Mary Rezende Faleiro ${ }^{1}$

\section{Resumo}

O GMC intensivo, apoiado na evolução da metodologia do GMC atual, é um grupo de trabalho no qual os desempenhos dos processos são analisados e melhorados expressivamente em um curto espaço de tempo. Surgiu na indústria automobilística japonesa e consiste na melhoria contínua dos processos com base no envolvimento das pessoas e o trabalho em pequenos grupos. As principais diferenças estão na velocidade de condução da análise e da implementação das ações, além da maior disponibilidade e dedicação dos integrantes do grupo e do gestor. Foi formado um grupo de 9 pessoas para reduzir a queda de carvão vegetal nas correias transportadoras e em seus entroncamentos, com integrantes da produção e da manutenção. Durante a "semana de execução", o grupo ficou 100\% disponível para planejar e executar ações levantadas para solução dos problemas de queda do carvão vegetal. Após essa semana, o grupo teve mais quatro meses para fechamento e sustentação das ações. O resultado do grupo foi uma redução da queda de carvão vegetal em $49 \%$, para uma meta inicial de $20 \%$, o qual representa cerca de 183t de carvão vegetal por mês.

Palavras-chave: Melhoria contínua de processos; Análise; Implementação de ações; Queda de carvão vegetal.

\section{METHODOLOGY OF CIT (CONTINUOUS IMPROVEMENT TEAM) INTENSIVE TO REDUCE CHARCOAL FALL IN CONVEYOR BELTS}

\section{Abstract}

The CIT intensive, supported in the evolution of the current CIT methodology, is a working group in which process performances are analyzed and improved dramatically in a short space of time. It appeared in the Japanese automotive industry and it is process continuous improvement based on people involvement and work in small groups. The main differences are in the conduction velocity of analysis and actions implementation, beyond greater availability and dedication of the team members and manager. A group of 9 people was formed to reduce charcoal fall on conveyor belts and its junctions, with production and maintenance members. During the "week of implementation", the team was 100\% available to plan and execute actions to solve the problems of charcoal fall. After this week, the group had four months to close and support actions. The team result was a charcoal fall reduction at $49 \%$ for an initial target of $20 \%$, which is about 183 tons charcoal per month.

Keywords: Process continuous improvement; Analyses; Implementation of actions; Charcoal fall.

1 Bacharel e Mestre em Estatística pela UFMG. Doutora em Engenharia Metalúrgica pela UFMG. Coordenadora Técnica da Gerência de Matérias-Primas e Produção de Ferro-Gusa, Vallourec Tubos do Brasil, Belo Horizonte, Minas Gerais, Brasil.

* Contribuição técnica ao $44^{\circ}$ Seminário de Redução de Minério de Ferro e Matérias-primas, 15o Simpósio Brasileiro de Minério de Ferro e $2^{\circ}$ Simpósio Brasileiro de Aglomeração de Minério de Ferro, 15 a 18 de setembro de 2014, Belo Horizonte, MG, Brasil. 


\section{INTRODUÇÃO}

O carvão vegetal corresponde a cerca de $45 \%$ do custo de produção do ferro-gusa na Vallourec Tubos do Brasil. A queda de carvão ocasiona: i) perda total do carvão que não é recirculado; ii) custo de limpeza e de recirculação do material que sofreu queda; e iii) perda da qualidade do carvão que sofre queda (em termos de granulometria e composição química), o que gera um consumo adicional de carvão pelos altos-fornos.

A estimativa mensal de queda de carvão é de 374t, considerando 10 pontos principais de queda em correias transportadoras e em seus entroncamentos.

Foi formado um GMC intensivo, composto por 9 integrantes da produção e da manutenção, para reduzir a queda de carvão vegetal nas correias transportadoras e em seus entroncamentos em no mínimo $20 \%$.

O GMC intensivo, apoiado na evolução da metodologia do GMC atual [1], é um grupo de trabalho no qual os desempenhos dos processos são analisados e melhorados expressivamente em um curto espaço de tempo. Surgiu na indústria automobilística japonesa e consiste na melhoria contínua dos processos com base no envolvimento das pessoas e o trabalho em pequenos grupos. As principais diferenças estão na velocidade de condução da análise e da implementação das ações, além da maior disponibilidade e dedicação dos integrantes do grupo e do gestor.

Durante a "semana de execução", o grupo ficou 100\% disponível para planejar e executar ações levantadas para solução dos problemas de queda do carvão vegetal. Após essa semana, o grupo teve mais 4 meses para fechamento e sustentação das ações. O resultado do grupo foi uma redução da queda de carvão vegetal em 49\%, que representa cerca de 183 t de carvão vegetal por mês

\section{MATERIAIS E MÉTODOS}

O GMC intensivo utiliza como princípios: i) resolver os problemas no local onde as coisas acontecem; ii) resolver os problemas reais; III) e resolver os problemas com dados reais.

O trabalho do GMC é um processo que segue o método DMAICS [2]:

$D$ - Define (Definir);

M - Measure (Medir);

A - Analyse (Analisar);

I - Improve (Melhorar/Implementar);

C - Control (Controlar/Checar eficácia );

$\mathrm{S}$ - Standardize (Padronizar).

O tempo de duração de um GMC intensivo é de aproximadamente 5 meses e funciona conforme metodologia descrita na Figura 1:

\footnotetext{
* Contribuição técnica ao $44^{\circ}$ Seminário de Redução de Minério de Ferro e Matérias-primas, 15ํ Simpósio Brasileiro de Minério de Ferro e $2^{\circ}$ Simpósio Brasileiro de Aglomeração de Minério de Ferro, 15 a 18 de setembro de 2014, Belo Horizonte, MG, Brasil.
} 


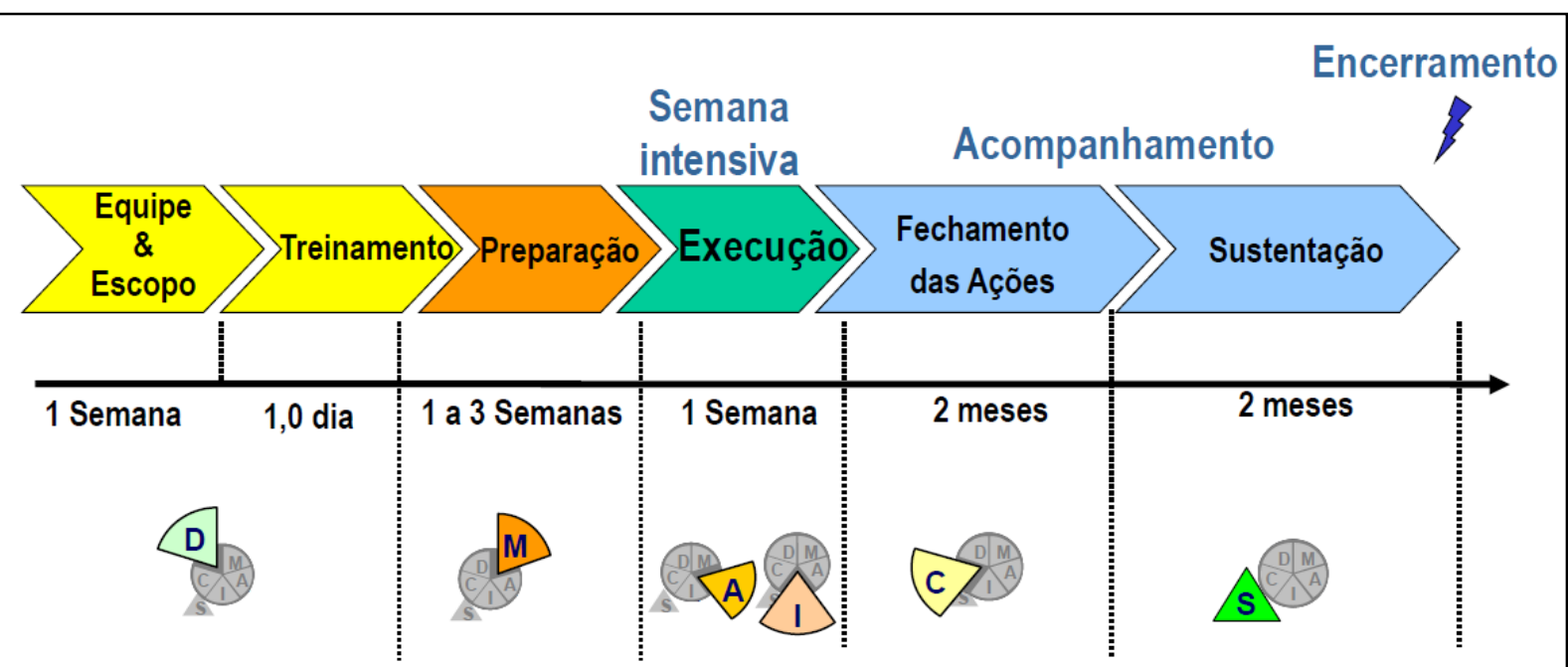

Figura 1. Metodologia do GMC intensivo.

\subsection{Equipe \& Escopo}

$\mathrm{Na}$ abertura de um GMC intensivo devem ser considerados: a necessidade dos clientes (internos ou externos), o alinhamento com a estratégia da empresa, as metas estabelecidas para a unidade e a definição de temas específicos, não amplos. Em suma, o grupo deve ter um escopo bem definido, resolver problemas mais simples e estar totalmente disponível.

O líder do grupo precisa querer ser o líder, ser pró-ativo, ter senso de urgência, ter domínio da metodologia do GMC, ser comprometido, ter conhecimento do processo, ter boa rede de relacionamento e conseguir influenciar e direcionar as pessoas.

Os integrantes precisam dar suporte ao líder, ser pró-ativo, dividir com os grupos as informações e não ter medo de errar.

O GMC intensivo "Reduzir queda de carvão vegetal nas correias transportadoras" foi formado com membros da operação, do processo e da manutenção da área. Tanto o escopo quanto os perfis dos integrantes e do líder atendiam aos critérios exigidos.

\subsection{Treinamento}

O treinamento sobre a metodologia do GMC intensivo teve duração de um dia, e abrangeu os assuntos de ferramentas de qualidade e método de análise e soluções de problemas.

\subsection{Preparação}

É na etapa de preparação que o grupo coleta as informações necessárias para a semana intensiva do grupo, verifica se os dados são confiáveis, define indicadores e a situação atual. Essa etapa dura em média de 1 a 3 semanas, mas para o grupo "Reduzir queda de carvão vegetal nas correias transportadoras" durou 6 semanas. Isso porque foi necessário quantificar a queda de carvão nos 10 principais pontos de queda. Para cada ponto, coletou-se a queda de carvão durante $3 \mathrm{~h}$, em 3 dias distintos e tirou-se a média dos 3 dias. Com isso, estimou-se a queda de carvão durante o mês em cada ponto e no total. Também foi feito um mapeamento do processo (fluxo de carvão) e Pareto para identificar os pontos de queda mais

\footnotetext{
* Contribuição técnica ao 44ํㅗㄴ Seminário de Redução de Minério de Ferro e Matérias-primas, 15오 Simpósio Brasileiro de Minério de Ferro e 2ํ Simpósio Brasileiro de Aglomeração de Minério de Ferro, 15 a 18 de setembro de 2014, Belo Horizonte, MG, Brasil.
} 
críticos. Através de Brainstorming, foram levantadas e estudadas as principais causas de queda de carvão.

\subsection{Execução}

No $1^{\circ}$ dia da semana intensiva foi feito um Brainstorming para levantar e planejar as ações para os próximos dias da semana intensiva. Durante os $2^{\circ}$, $3^{\circ}$ e $4^{\circ}$ dias, algumas ações foram implementadas. No final de cada dia, aconteceu uma reunião com o gestor da área para que ele pudesse acompanhar e auxiliar o grupo com os recursos necessários. No $5^{\circ}$ e último dia, as principais ações foram padronizadas e o grupo realizou uma visita à área com o gestor. No final do dia, foi feita uma apresentação geral do trabalho do grupo.

\subsection{Fechamento das Ações}

O grupo manteve reuniões semanais para acompanhamento das ações. A maioria das ações que não foram concluídas durante a semana intensiva, tiveram a implementação nos 2 meses seguintes na fase de fechamento das ações.

\subsection{Sustentação}

Após a fase de fechamento das ações, quantificou-se novamente a queda de carvão nos 10 principais pontos de queda. Assim como na fase de preparação, para cada ponto, coletou-se a queda de carvão durante $3 \mathrm{~h}$, em 3 dias distintos e tirou-se a média dos 3 dias. Dessa forma, foi possível comparar o indicador antes e após a implementação das ações do grupo.

\section{RESULTADOS E DISCUSSÃO}

Estimou-se que a queda de carvão vegetal das correias transportadoras e seus entroncamentos fosse de $374 t$ por mês. Dessas, 351t são reaproveitadas e 23t são perdidas em forma de pó para o ambiente.

A meta proposta para o grupo foi de reduzir essa queda em no mínimo $20 \%$, ou seja, baixar de $374 \mathrm{t} / \mathrm{mês}$ para $299 \mathrm{t} /$ mês ou menos (Figura 2 ).

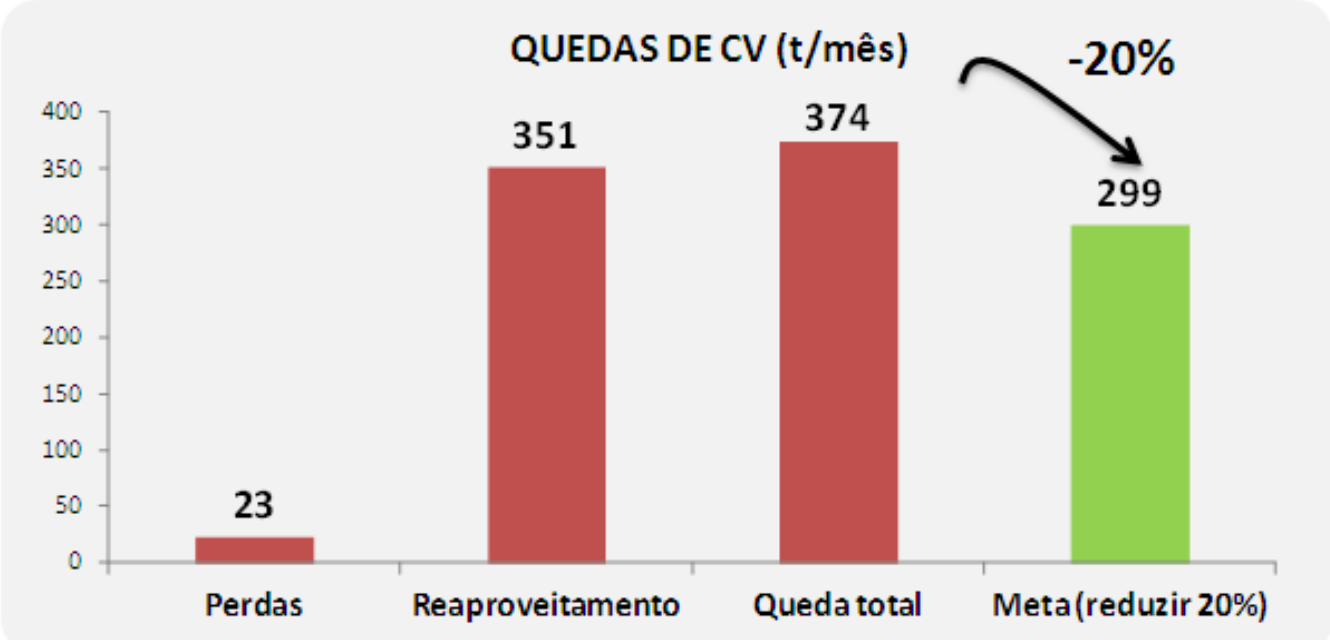

Figura 2. Indicador de queda de carvão e meta proposta.

\footnotetext{
* Contribuição técnica ao $44^{\circ}$ Seminário de Redução de Minério de Ferro e Matérias-primas, 15ํ Simpósio Brasileiro de Minério de Ferro e $2^{\circ}$ Simpósio Brasileiro de Aglomeração de Minério de Ferro, 15 a 18 de setembro de 2014, Belo Horizonte, MG, Brasil.
} 
A Figura 3 mostra o mapeamento dos fluxos de carvão elaborados pelo grupo durante a fase de preparação, com a identificação dos 10 pontos principais de queda de carvão.

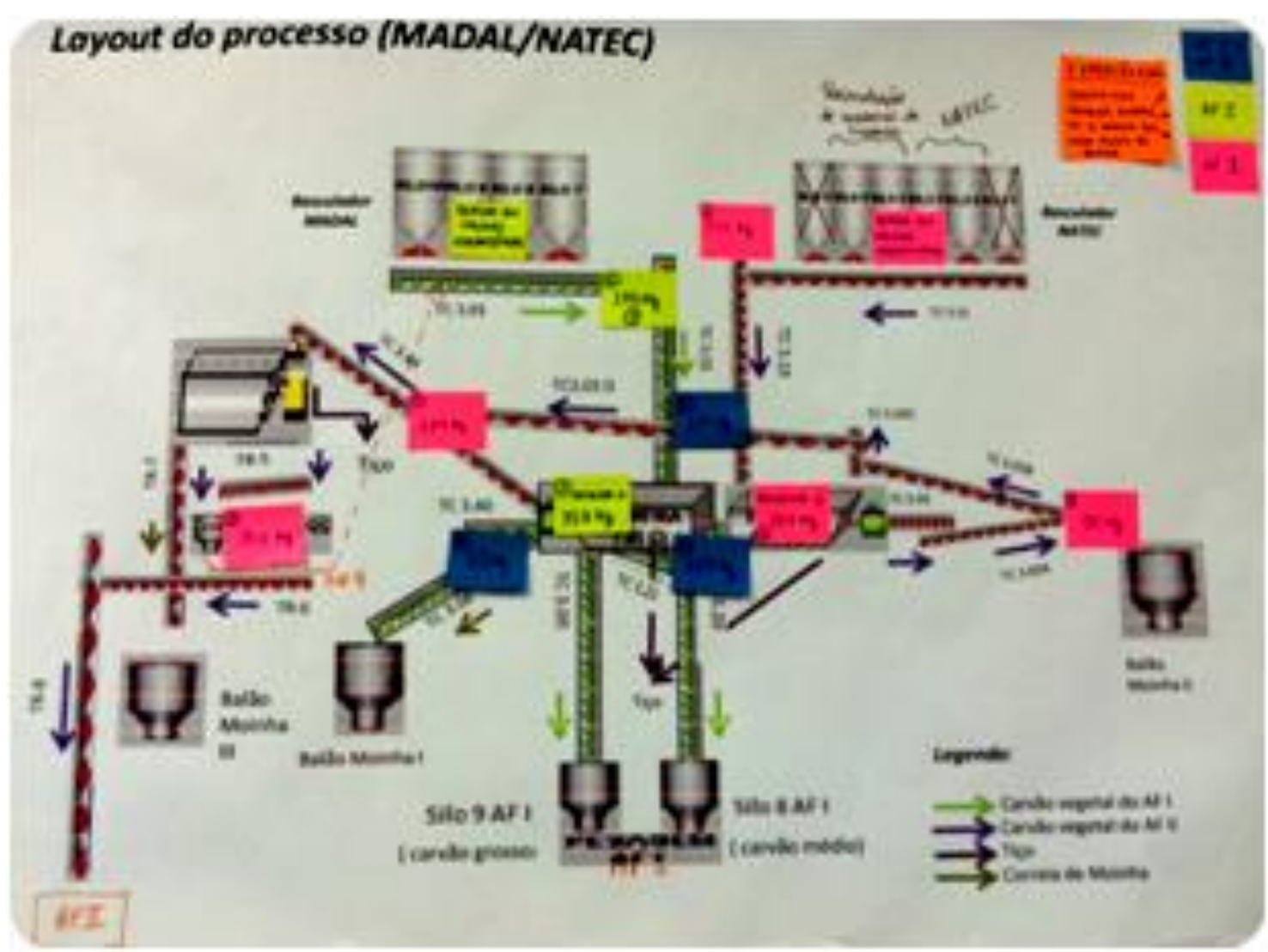

Figura 3. Mapeamento do fluxo de carvão com os 10 pontos principais de queda identificados.

Foram identificados 4 pontos críticos de queda de carvão, os quais juntos representam $66 \%$ do total, conforme ilustrado no Pareto da Figura 4.

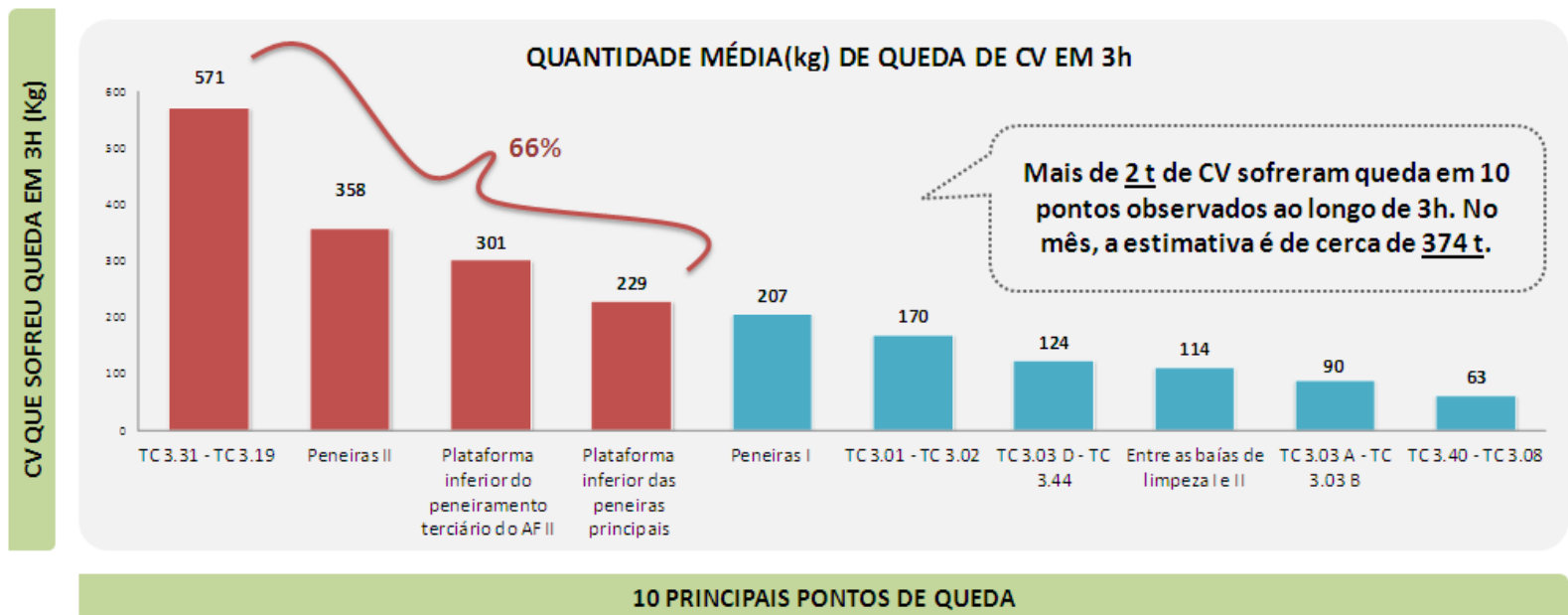

Figura 4. Pareto dos 10 pontos de queda de carvão vegetal.

O próximo passo foi a identificação das causas de queda de carvão nos pontos críticos através de um Brainstorming com os integrantes do grupo e operadores da área. O principal vilão encontrado foi o tiço. Isso porque quando ele chega até a

* Contribuição técnica ao 44 Seminário de Redução de Minério de Ferro e Matérias-primas, $15^{\circ}$ Simpósio Brasileiro de Minério de Ferro e $2^{\circ}$ Simpósio Brasileiro de Aglomeração de Minério de Ferro, 15 a 18 de setembro de 2014, Belo Horizonte, MG, Brasil. 


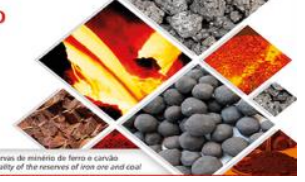

correia transportadora, ele agarra nos rolos fazendo com que haja a queda de carvão vegetal e causando outros problemas, como desalinhamento ou rasgação das correias.

A partir daí, foram definidas 3 frentes de trabalho:

1) Evitar que o tiço chegue à usina;

2) Evitar que o tiço chegue até as correias transportadoras;

3) Aprender a conviver com o tiço.

Foram criadas ações considerando cada uma das frentes de trabalho e, em seguida, as ações foram priorizadas utilizando a matriz de priorização ilustrada na Figura 5, que leva em conta o nível de dificuldade da ação e seu impacto no indicador.

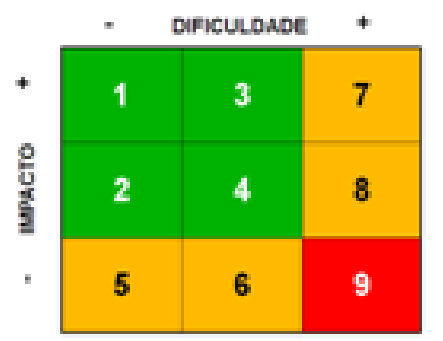

Figura 5. Matriz de priorização.

O ideal seria atacar a 1a frente, ou seja, evitar que o tiço chegue à usina. No entanto, a maioria das ações relacionadas com essa frente eram ações de longo-prazo ou de investimento (como treinar operadores para não carregar tiços ou implementar separador de tiço nas fazendas), e não poderiam ser resolvidas dentro da semana intensiva. Para essa frente, a ação imediata que foi criada e implementada foi a de executar procedimento de devolução de carga com tiço e elaboração de ranking das piores fazendas.

A $2^{\text {a }}$ frente de trabalho foi evitar que o tiço entrasse nas correias caso ele chegasse à usina. Essa frente também incluía ações de longo-prazo e/ou investimento, como instalar grelhas vibratórias inclinadas separadoras de tiço no topo dos silos de recebimento de carvão na usina. Durante a semana intensiva, foi construída uma grelha não-vibratória, mas a mesma não foi eficiente por reter material agarrado na abertura das malhas.

A 3 $3^{\text {a }}$ frente foi a de aprender a conviver com o tiço caso ele chegasse à usina e às correias transportadoras. Esse foi o foco do trabalho na semana intensiva. As ações que foram priorizadas foram: revisar e retornar com o plano de manutenção preventiva; redimensionar os pontos de recebimento de carvão nos chutes das correias; alinhar correias; repor suportes, rolos e laterais; melhorar fixação das guias laterais de borracha; revisar padrões (com foco em visual); resgatar manuais; adequar capacidade e velocidade das correias e da transferência das calhas; eliminar recirculação dos tiços; criar dispositivo para limpeza da tela secundária $(10 \mathrm{~mm})$ das peneiras; criar check-list de verificação das não conformidades para abertura de notas de manutenção; definir padrinhos para cada área/equipamento; criar estoque mínimo de sobressalente.

O grupo manteve reuniões semanais para acompanhamento das ações. A maioria das ações que não foram concluídas durante a semana intensiva, tiveram a implementação nos 2 meses seguintes na fase de fechamento das ações.

Após a fase de fechamento das ações, quantificou-se novamente a queda de carvão nos 10 principais pontos de queda. Assim como na fase de preparação, para cada ponto, coletou-se a queda de carvão durante $3 \mathrm{~h}$, em 3 dias distintos e tirou-se a

* Contribuição técnica ao $44^{\circ}$ Seminário de Redução de Minério de Ferro e Matérias-primas, 15오 Simpósio Brasileiro de Minério de Ferro e 2ํ Simpósio Brasileiro de Aglomeração de Minério de Ferro, 15 a 18 de setembro de 2014, Belo Horizonte, MG, Brasil. 
média dos 3 dias. Dessa forma, foi possível comparar o indicador antes e após a implementação das ações do grupo, conforme ilustrado na Figura 6.

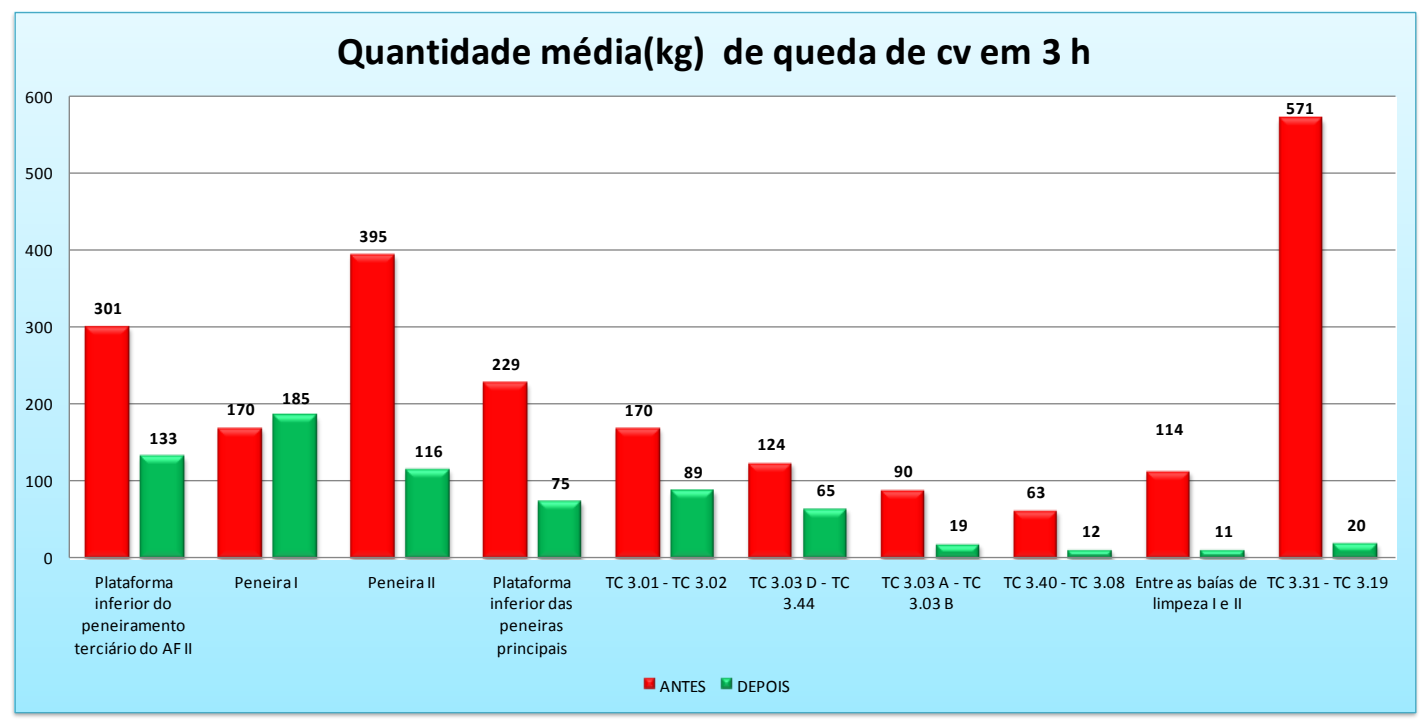

Figura 5. Matriz de priorização.

Observou-se uma redução total de $49 \%$ na queda de CV, o que equivale a uma redução de: 1 t em 3h, 183t por mês e 2.196t por ano.

\section{CONCLUSÃO}

A metodologia de GMC intensivo permite analisar e melhorar expressivamente o desempenho dos processos em um curto espaço de tempo, com base no envolvimento das pessoas e o trabalho em pequenos grupos.

O grupo formado na Vallourec Tubos do Brasil conseguiu reduzir em 49\% (cerca de $183 \mathrm{t} / \mathrm{mês}$ ) a queda de carvão vegetal nas correias transportadoras e seus entroncamentos, superando a meta inicial de $20 \%$. Além da economia com carvão vegetal, o grupo obteve outros ganhos como: segurança e qualidade do trabalho, qualidade de limpeza da área, menor ocupação dos equipamentos de transporte e redução da circulação de particulados.

\section{Agradecimentos}

A autora e líder do GMC Intensivo "Reduzir Perdas de Carvão Vegetal" da Vallourec Tubos do Brasil agradece a todos os integrantes do grupo e demais que contribuíram para o sucesso desse trabalho.

\section{REFERÊNCIAS}

1 Chaves NMD. Soluções em Equipe: Como desenvolver equipes de Melhoria Contínua e obter resultados para as pessoas e organizações. Belo Horizonte: Editora Falconi; 2001.

2 Silva A. Integração das Ferramentas da Qualidade ao PDCA e ao Programa Seis Sigma. Belo Horizonte: Editora DG; 2002.

* Contribuição técnica ao 44ํㅗㄴ Seminário de Redução de Minério de Ferro e Matérias-primas, $15^{\circ}$ Simpósio Brasileiro de Minério de Ferro e $2^{\circ}$ Simpósio Brasileiro de Aglomeração de Minério de Ferro, 15 a 18 de setembro de 2014, Belo Horizonte, MG, Brasil. 